\title{
Incomplete taste adaptation to different concentrations of salt and sugar solutions
}

\author{
CYNTHIA N. DuBOSE, HERBERT L. MEISELMAN, \\ DEBORAH A. HUNT, and DAY WATERMAN \\ Behavioral Sciences Division, Food Sciences Laboratory \\ U.S. Army Natick $R \&$ D Command, Natick, Massachusetts 01760
}

\begin{abstract}
Two concentrations each of sodium chloride and sucrose solutions were used as stimuli in a study examining taste adaptation. Twenty subjects were presented a 3-min continuous flow of each taste stimulus over the anterior dorsal tongue surface, and periodically gave magnitude estimates of its intensity. The degree of adaptation was greater for the less concentrated solutions than for the more concentrated ones, but the majority of subjects did not adapt completely to any of the stimuli. This result, which is consistent with other reports from this laboratory, is discussed in terms of individual differences among subjects and in relation to recent taste research based on completely adapted subjects.
\end{abstract}

Much of the literature on adaptation in taste asserts that most subjects show complete and relatively rapid adaptation to moderately intense taste stimuli (Abrahams, Krakauer, \& Dallenbach, 1937; Bartoshuk, 1968; Hahn, 1934, Pfaffman, 1965). However, in four separate studies using a total of 74 subjects, Meiselman and his co-workers have shown that only a relatively small percentage of subjects report complete adaptation to moderately intense salt $(\mathrm{NaCl})$ solutions (Meiselman, 1968, 1972, 1975; Meiselman \& DuBose, 1976). These studies have determined the proportion of the population exhibiting complete taste adaptation and have investigated factors determining degree of adaptation.

One such factor is method of stimulus presentation. Presenting the stimulus as a continuous flow over the anterior dorsal surface of the tongue is more likely to produce complete adaptation than either using a whole mouth flow presentation or having the subject sip the stimulus solution (Meiselman, 1972). Another factor is the nature of the response task; a hand-raise task (in which raising the hand indicates the absence of taste) and a cross adaptation procedure are more likely to encourage reports of complete adaptation than is a magnitude estimation task (Meiselman, 1975). A third factor, instructional set, was shown not to have a significant effect on the subjects' reporting complete adaptation (Meiselman \& DuBose, 1976).

Although these situational factors are related to degree of adaptation, there also seem to be consistent individual differences in the tendency to adapt or not adapt. Meiselman (1972) examined individual data from his adaptation study using four different stimulus presentation methods and two different stimulus compounds. He showed that some subjects adapted more readily than others during all proce- dures. Meiselman and DuBose (1976) examined their data from individual subjects and reported that $75 \%$ of their subjects were consistent in their tendency to adapt or not adapt over a series of trials and sessions.

In their experiment, Meiselman and DuBose used two salt $(\mathrm{NaCl})$ solutions, $.36 \mathrm{M}$ and $.50 \mathrm{M}$, as stimuli. Although they attributed their failure to observe complete adaptation simply to nonadapting subjects, it may have been due to the subject's reporting magnitude estimates of the intensity of tactile properties of the stimuli which are not related to taste. This possibility was suggested by McBurney (1966) regarding his own subjects who did not show complete adaptation in a continuous dorsal flow adaptation task. $\mathrm{NaCl}$ has been characterized as having a "stinging" quality at relatively high concentrations (Abrahams et al., 1937; Holway \& Hurvich, 1937), and the subject may have been responding to sensations associated with stinging, burning, etc.

The present experiment was conducted to examine the adaptation functions to solutions of a taste stimulus (sucrose) not reported to have any stinging quality and to compare them with the adaptation functions to approximately equally intense $\mathrm{NaCl}$ solutions. One of the stimuli was a lower concentration of salt than was used in the previous study (as well as a matched sucrose) to serve as a further check on stinging.

\section{METHOD}

\section{Subjects}

Twenty male and female laboratory personnel served as subjects. Their ages ranged from 19 to 40 years. All subjects were practiced in magnitude estimation scaling but did not know the purpose of the experiment. 
Stimuli

Two concentrations of sucrose, $.36 \mathrm{M}$ and $.10 \mathrm{M}$, and two concentrations of $\mathrm{NaCl}, .36 \mathrm{M}$ and $.10 \mathrm{M}$, were used as stimuli. The concentrations were chosen to be approximately equally intense at each of the two concentration levels. The solutions were prepared using distilled water and reagent grade chemicals. During the experimental session, they were kept in four glass containers in a water bath maintained at $36^{\circ} \mathrm{C}$. The solutions were delivered to the subject through Tygon tubing, and three two-way stopcocks directed the flow from each of the four containers to the subject. The solutions flowed over the subject's tongue at approximately $5 \mathrm{ml} / \mathrm{sec}$.

\section{Procedure}

The subject was seated with his head resting firmly in a chinrest, with his tongue extended into a tongue fixation apparatus (Meiselman \& Halpern, 1973). Each trial consisted of a continuous 3-min flow of a stimulus solution over the anterior dorsal surface of the tongue. The subjects were instructed to give magnitude estimates of the solution's intensity every $15 \mathrm{sec}$ upon the signal of the experimenter. The estimates were relative to a modulus of 10 which was assigned to the solution upon initial contact with the subject's tongue. At the end of the $3 \mathrm{~min}$, the subject rated the intensity of a brief flow $(5 \mathrm{sec})$ of a "new solution" and described its quality, as in a cross-adaptation task (McBurney \& Bartoshuk, 1973). The "new solution" was the same stimulus the subject had tasted for the previous $3 \mathrm{~min}$.

There was a distilled water rinse and a 3-min rest between trials for each subject. All four stimuli were presented to each subject in one session. They were presented in random order with the restriction that neither the two salt solutions nor the two sucrose solutions followed each other.

Specific instructions, which were read to the subject at the start of the session, are shown in the Appendix. The wording was deliberately neutral in terms of what changes in the solution intensity the subject might expect during the 3-min flow.

The subjects recorded their own judgments on data sheets attached to a vertical surface at eye level.

\section{RESULTS}

For each stimulus, the median magnitude estimates for each $15-\mathrm{sec}$ time interval were calculated and are plotted in Figure 1. An analysis of variance of the magnitude estimates yielded significant effects of

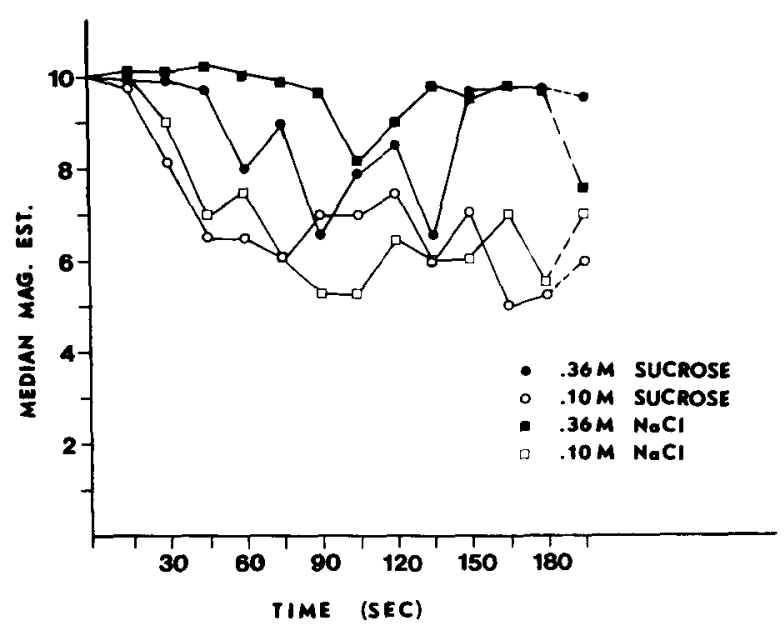

Figure 1. Median magnitude estimates at 15-sec intervals during 3-min anterior dorsal flow adaptation tasks. Each subject $(N=20)$ was tested with each stimulus.
Table 1

\begin{tabular}{|l|c|c|}
\hline St inulus & $\begin{array}{c}\text { Percentage of Subjects } \\
\text { Reporting Zero } \\
\text { Once }(\mathrm{N}=20)\end{array}$ & $\begin{array}{c}\text { Percentage of Subjects } \\
\text { Report ing Zero } \\
\text { Twice in Succession } \\
\text { (N=20) }\end{array}$ \\
\hline $.36 \mathrm{M}$ Sucrose & 35 & 25 \\
\hline $.10 \mathrm{M} \mathrm{Sucrose}$ & 45 & 30 \\
\hline \hline $.36 \mathrm{M} \mathrm{MaCl}$ & 35 & 20 \\
\hline $.10 \mathrm{M} \mathrm{MaCl}$ & 50 & 25 \\
\hline
\end{tabular}

concentration $(F=4.43, \mathrm{df}=1,19, \mathrm{p}<.05)$ and time $(\mathrm{F}=6.16$, df $=12,228, \mathrm{p}<.01)$. The adaptation functions for the salt and sucrose solutions are similar at each of the two concentration levels, and the degree of adaptation for the weaker concentrations is greater than that for the stronger concentrations.

If complete adaptation is defined as an estimate of zero magnitude, the percentages of subjects showing complete adaptation are shown in Table 1 . The percentage of subjects reporting zero at least once at any time during the 3-min trial is shown for each stimulus. The percentage of subjects showing continued complete adaptation, defined as reports of zero magnitude twice in succession, is also shown for each stimulus. Fewer subjects displayed complete adaptation with the stronger stimuli $(35 \%$ in both cases) than with the weaker ones (45\%-50\%). Using the more stringent adaptation criterion, even fewer subjects showed continued complete adaptation in all four conditions $(20 \%-30 \%)$.

At the end of the 3-min flow, the subjects rated the intensity of the "new solution" (which was a brief pulse of the same stimulus) and described its quality. The median intensity estimates are shown as the last points of the functions in Figure 1. The quality judgments for each of the stimuli are shown in Table 2. Sixty percent of the subjects reported that the $\mathrm{NaCl}$ stimuli still tasted salty after $3 \mathrm{~min}$. For the sucrose stimuli, $\mathbf{7 0 \%}$ of the subjects reported that the $.36 \mathrm{M}$ solution still tasted sweet, and $40 \%$ of the subjects reported that .1 M tasted sweet.

\section{DISCUSSION}

The majority of the subjects used in this study did not adapt completely to either the salt or the sucrose stimuli, although the degree of adaptation was significantly greater for the weaker solutions than for the more concentrated ones. This latter result is consistent with previous reports that subjects adapt more quickly to weaker stimuli than to stronger ones (Abrahams et al., 1937; Bujas, 1953; Hahn, 1949). It has also been reported that $\mathrm{NaCl}$ adapts more readily than sucrose, but that the difference is more in the completeness of adaptation than in the speed (Hahn, 1934). Our results indicate that neither stimulus adapts completely in a time interval 
Table 2

Frequencies of Stimulus Quality Descriptions by Subjects $(N=20)$

\begin{tabular}{|l|c|c|c|c|c|c|c|}
\hline & So Taste & Salcy & Sweet & Sour & Bitter & Other & Tot a1 \\
\hline .36 M NaC1 & 5 & 12 & 1 & 1 & 1 & 0 & 20 \\
\hline .10 M MaC1 & 6 & 12 & 0 & 2 & 0 & 0 & 20 \\
\hline \hline $\begin{array}{l}.36 \mathrm{M} \\
\text { Sucrose }\end{array}$ & 5 & 0 & 14 & 0 & 0 & 1 & 20 \\
\hline $\begin{array}{l}.10 \mathrm{M} \\
\text { Sucroec }\end{array}$ & 9 & 0 & 8 & 1 & 2 & 0 & 20 \\
\hline
\end{tabular}

which is much longer than is normally used in experiments of this type.

That the majority of the subjects used in this study did not adapt completely to any of the stimuli is consistent with the results of our previous study (Meiselman \& DuBose, 1976), which suggested that part of the population simply does not adapt readily to taste stimuli and that nonadapters seem to be a larger segment of the population than the adaptation literature indicates. In the present study, 6 of the 20 subjects completely adapted to every stimulus, while 8 of the 20 subjects did not adapt completely to any stimulus. These two subgroups were examined separately, and their median magnitude estimates for the four stimuli are plotted in Figures 2 and 3. Of the remaining 6 subjects, 5 subjects completely adapted to one or both of the weaker stimuli, and 1 subject completely adapted only to $.36 \mathrm{M} \mathrm{NaCl}$. Thus, in this study, $70 \%$ of the subjects were consistent in their tendency to adapt or not adapt to a variety of taste stimuli. Our previous study (1976) reported that 14 of the 18 subjects $(78 \%)$ were consistent in their response to $.36 \mathrm{M} \mathrm{NaCl}$ over three trials and that 9 of the 12 subjects $(75 \%)$ were consistent in their response to $.50 \mathrm{M} \mathrm{NaCl}$ over three sessions.

There were no verbal reports from our subjects indicating that they were responding to any attribute of the stimuli other than taste intensity. The instructions specifically asked for estimates of the intensity of the taste. The possibility that tactile irritation or sensation confounded the adaptation to $\mathrm{NaCl}$ stimuli was not supported. The adaptation to sucrose stimuli which were comparable to the $\mathrm{NaCl}$ stimuli in perceived intensity was no more complete than the adaptation to $\mathrm{NaCl}$. Abrahams et al., (1937) reported that subjects complained of a stinging, painful quality of the stimulus in the range between $1.66 \mathrm{M}$ and $3.93 \mathrm{M} \mathrm{NaCl}$. Stinging was not observed at $.84 \mathrm{M} \mathrm{NaCl}$ in their study. The $\mathrm{NaCl}$ stimuli used in the present study were well below the range of Abrahams' stimuli.

Additional data gathered recently in this laboratory (Hunt, personal communication) indicate that $75 \%$ of the subjects report zero when asked to scale the intensity of stinging during a brief dorsal flow presentation of $\mathrm{NaCl}$ stimuli ranging from $.10 \mathrm{M}$ to
$.40 \mathrm{M}$. Also, less than $11 \%$ of the subjects describe stimuli as stinging in the range of $.10 \mathrm{M}$ to $.40 \mathrm{M} \mathrm{NaCl}$ in both sip and flow tasks when asked to check attributes of taste stimuli from a list. This finding, along with our data on sucrose, strengthens our contention that nonadapting subjects continue to experience the taste of the stimulus during the adaptation period.

Therefore, in contrast to other published reports, we have repeatedly failed to observe complete taste adaptation in the majority of subjects. Our attempt to determine which methodological factors have influenced these findings has revealed that many

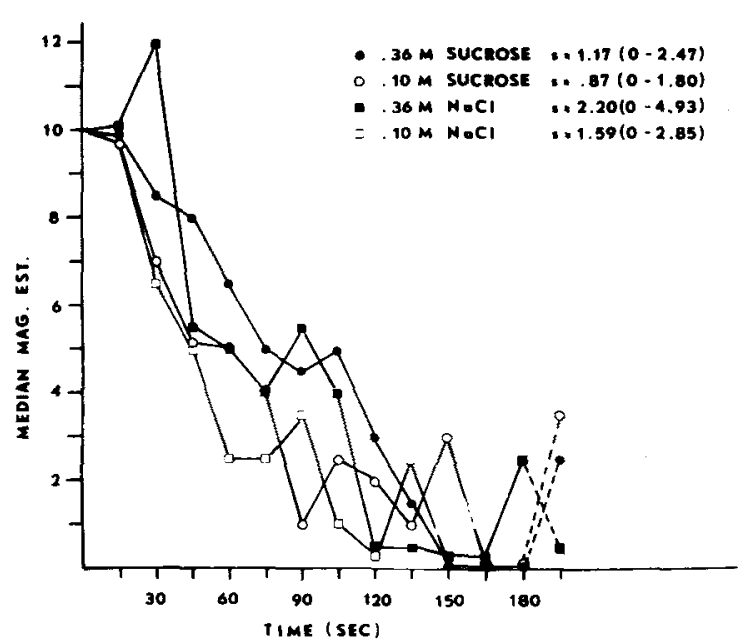

Figure 2. Median magnitude estimates at 15-sec intervals during 3-min adaptation tasks. Data are from 6 of the 20 subjects who completely adapted to all four stimuli. A measure of variability of the magnitude estimates, $\delta_{\operatorname{mdn}}\left[=.93\left(Q_{3}-Q_{1}\right) / n\right]$, was calculated for each median plotted. The range of $\delta_{\text {mdn }}$ for the 14 time periods for each stimulus is shown in parentheses. The mean, $\mathbf{s}$, of the $14 \delta_{\text {mdn }}$ values is also shown for each stimulus.

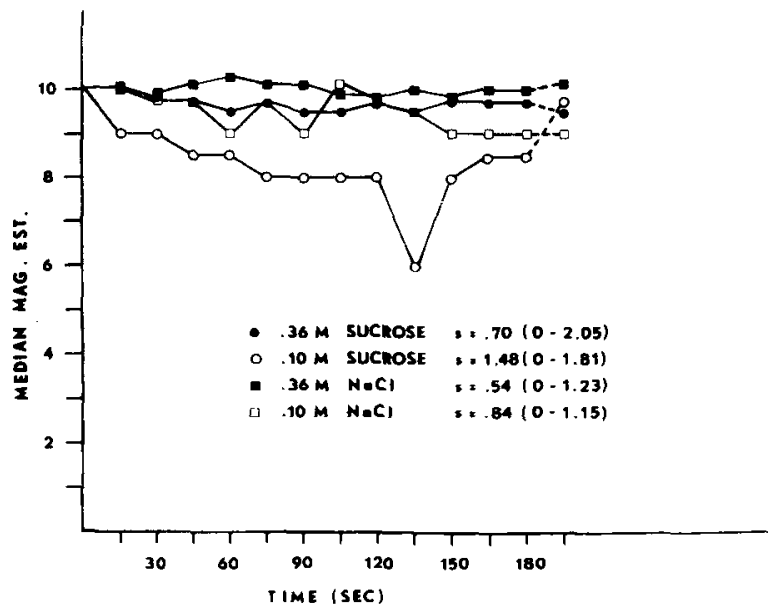

Figure 3. Median magnitude estimates at $15-\mathrm{sec}$ intervals during 3-min adaptation tasks. Data are from 8 of the 20 subjects who did not adapt completely to any of the four stimuli. The mean and range of $d_{\text {mdn }}$ are shown for each stimulus. 
variables are involved. Stimulus type, stimulus concentration, presentation procedure, and response task are important variables. Our work has shown that there are important differences within the group of subjects as well, and that many subjects will not report complete adaptation even under conditions most conducive to it. A small percentage of the subjects will report complete adaptation under a variety of conditions.

In much recent taste research, tests are based upon the responses of a completely adapted subject. The assumption that the subject is completely adapted to a continuous stimulus before the "test stimulus" is administered is called into serious question by our results, since subjects who do adapt completely are in the minority. In addition, utilizing subjects who do completely adapt makes generalization to the larger population of nonadapters questionable.

\section{APPENDIX}

\section{Instructions for Subjects}

In this experiment a solution will flow over your tongue for several minutes. You will be asked to rate the strength of this solution every 15 seconds. When I say "now" you will rate the solution.

The initial solution will be assigned a rating of 10 . The solution's strength may change over the course of the several minutes. It may decrease, increase, or disappear. Your task will be to note these changes (every 15 seconds). If the solution becomes twice as strong, call it 20 . If it is half as strong, call it 5 . If it has no taste, call it zero. Feel free to use any number.

After several minutes, a new solution will flow over your tongue. I will tell you when this new solution is being introduced to you by saying "new solution." After a brief flow of the solution, I want you to tell me if the second solution had a taste, and, if so, what it was. Please estimate the strength of the new solution in proportion to the strength of the initial solution. If it is twice as strong, call it 20. If it is half as strong, call it 5. And so on. Feel free to use any number.
To summarize, while a solution flows over your tongue for several minutes, you will rate the strength every 15 seconds. When I say "new solution" tell me if the solution has a taste, if so, what it is, and rate its strength in comparison to the initial solution which is 10 .

Do you have any questions?

\section{REFERENCES}

Abrahams, H., Krakauer, D., \& Dallenbach, K. Gustatory adaptation to salt. American Journal of Psychology, 1937. 49. $462-469$.

Bartoshux, L. Water taste in man. Perception \& Psychophysics, $1968,3,69-72$.

Bujas, Z. L'adaptation gustatif et son mecanisme. Acta Instituti Psychologici, Universitatis Zagrebensis, 1953, 17, 1-10.

HahN, H. Die Adaptacion des Geschmachsinnes. Zeitschrift für Sinnesphysiologie, 1934. 65, 105.145.

Hakn, H. Beitrage zur Reizphysiologie. Heidelberg: Scherer, 1949.

Holway, A., \& Hurvich, L. Differential gustatory sensitivity to salt. American Journal of Psychology, 1937, 49, 37-48.

McBurney, D. Magnitude estimation of the taste of sodium chloride after adaptation to sodium chloride. Journal of Experimental Psychology, 1966, 72, 869-873.

MCBURNey, D. H., \& Bartoshuk, L. M. Interactions between stimuli with different taste qualities. Physiology and Behavior. 1973, 10, 1101-1106.

Merselman, H. Magnitude estimations of the course of gustatory adaptation. Perception \& Psychophysics, 1968, 4, 193-196.

Meiselman, H. Human taste perception. Chemical Rubber Company Reviews in Food Technology, April 1972, 89-119.

Meiselman, H. Effect of response task on taste adaptation. Perception \& Psychophysics, 1975, 17, 591-595.

Meiselman, H., \& DuBose, C. Failure of instructional set to affect completeness of taste adaptation. Perception \& Psychophysics, 1976, 19. 226-230.

Meiselman, H., \& Halpern, B. Enhancement of taste intensity through pulsatile stimulation. Physiology and Behavior, 1973, 11, 713-716.

Pfaffmann, C. L'adaptation gustative. Extrait des Actualites Neurophysiologiques, Sixième Série. Paris: Masson \& Cie, 1965. Pp. 85-97.

(Received for publication September 13, 1976; revision accepted October $15,1976$. 